\title{
“EN EL SUEÑO DEL HOMBRE QUE SOÑABA, EL SOÑADO SE DESPERTÓ”: AÇÃO E HISTÓRIA EM JORGE LUIS BORGES
}

\author{
Aurea Mota* \\ aureamota@ub.edu
}

\begin{abstract}
Nuestro destino (a diferencia del infierno de Swedenborg y del infierno de la mitología tibetana) no es espantoso por irreal; es espantoso porque es irreversible y de hierro. El tiempo es la substancia de que estoy hecho. El tiempo es un río que me arrebata, pero yo soy el río; es un tigre que me destroza, pero yo soy el tigre; es un fuego que me consume, pero yo soy el fuego. El mundo, desgraciadamente, es real; yo, desgraciadamente, soy Borges.
\end{abstract}

Jorge Luis Borges "Nueva refutación del tiempo"

RESUMO Neste artigo argumentamos que os temas da ação e da história presentes em alguns contos de Jorge Luis Borges antecipam alguns pontos que apareceram nas discussões pós-estruturalistas - nos campos da história, filosofia, antropologia - das últimas décadas do século XX. No seu labirinto literário-filosófico, especialmente por meio da ideia de destino, Borges explora elementos chave que se tornaram parte da noção de crítica que enfatiza as ideias de contingência e da impossibilidade de controle deliberado dos efeitos da ação humana em seu curso temporal.

Palavras-chave Jorge Luiz Borges, ação, história.

* Doutora pelo Instituto de Estudos Sociais e Pesquisa da UERJ e Professora da Universidade de Barcelona. Artigo recebido em 08/02/2013 e aprovado em 30/08/2013.

KRITERION, Belo Horizonte, nº 129, Jun./2014, p. 23-39 
ABSTRACT It is argued in this paper that the themes action and history present in some of Jorge Luis Borges's short stories have anticipated certain aspects of the post-structuralist debates - on history, philosophy, and anthropology - in the last decades of the twentieth century. In his literary and philosophical labyrinth, especially through the idea of destiny, Borges explores key elements that became part of the notion of critique that emphasize the idea of contingency and the impossibility of deliberated control of the effects of human action in its temporal course.

Keywords Jorge Luis Borges, action, history.

\section{Introdução}

Em seu ensaio autobiográfico ditado ${ }^{1}$ no início da década de 1970, o escritor argentino Jorge Luis Borges diz que "como la mayoría de mis parientes habían sido soldados y yo sabía que nunca lo sería, desde muy joven me avergonzó ser una persona destinada a los libros y no a la vida de acción". ${ }^{2}$ Leitores atentos de Borges podem estranhar essa passagem por algumas razões. A "autodetermin-ação" pessoal que está presente neste trecho revela uma concepção do agir humano e da estrutura que o circunscreve que pode ser repensada à luz da leitura de alguns contos escritos pelo próprio Borges. Pois, envolvendo o leitor um de seus labirintos, Borges é capaz de expor essa perspectiva sobre o seu destino como predeterminado, mas, ao mesmo tempo, ser reconhecido como alguém que conseguiu abstrair as marcas pessoais de sua história ${ }^{3}$ por meio da criação de um universo literário-filosófico revelador. Partindo dessa discussão sobre a autodestinação do próprio Borges, argumentamos neste artigo que a estratégia que o autor utiliza em seu esquema para o debate entre ação e estrutura está próximo do que propõe as revisões das ideias estruturalistas que ganharam força na segunda metade do século

1 A cegueira havia deixado Borges dependente de outras pessoas para seguir seu trabalho. Sua autobiografia foi redigida por Norman Thomas di Giovanni.

2 Borges, 1999, p. 24.

3 Sergio Miceli foi um dos únicos pesquisadores brasileiros a tratar da obra de Borges sob um ponto de vista mais filosófico e sociológico, e segundo este autor uma das marcas principais do trabalho do escritor argentino foi a habilidade para apagar sua história e separá-la de sua obra, por meio de recursos que nos permitem pensá-lo como "escritor nato". Segundo o autor: “Jorge Luis Borges, o único escritor latinoamericano com status de sumidade literária, teria logrado cancelar as marcas históricas de sua passagem pelo mundo social, que ele mesmo formatou como narrativa solipsista, autossuficiente, fora do tempo e do espaço" (Miceli, 2007, p. 157). 
XX, sobretudo com Jacques Derrida e outros filósofos franceses e, em outro campo e espaço, com Marshall Sahlins. ${ }^{4}$

Borges desenha em seus contos homens que têm objetivos e que os perseguem como se fossem a única coisa que importasse, desde o momento que a pretensão surge. $\mathrm{O}$ homem que age e que consegue alcançar seus objetivos é aquele que abandona todas as fórmulas de cálculo racional preestabelecido. Do ponto de vista filosófico, o homem que aparece nos contos de Borges, é visto como essência e experiência - conceito que transcende a própria subjetividade -, sua existência é algo que decorre desses dois princípios. Transparece por meio da leitura do conto "El Inmortal", por exemplo, que a existência concreta desse ser genérico é algo que pouco ajuda a compreender o que o homem "é". O realismo fantástico do autor pode ser visto como uma expressão da nostalgia que o autor sentia pela forma como a metafísica inseriu o homem no mundo e que, depois de corroído esse terreno, vê-se perdido em seus labirintos ainda não decifrados. ${ }^{5}$ Porém, como veremos, a metafísica que Borges reclama seria a de tipo "primordial", que se volta simplesmente para o que está além do concreto. ${ }^{6}$

Um exemplo desse tipo de personagem que busca alguma coisa e se entrega completamente à busca está no conto "Las Ruinas Circulares", que faz parte do livro "Ficciones" (original de 1944). O protagonista do conto é um "hombre taciturno" que "venía del Sur" e que percorreu um longo caminho simplesmente para sonhar com um homem "con integridad minuciosa y impornelo a la realidad". ${ }^{7}$ O protagonista só consegue alcançar seu objetivo quando declina de qualquer método que lhe possibilite, deliberadamente, atingi-1o. ${ }^{8}$ Em outro momento, não escapando de um dos principais debates

4 Para Cédola (1993, pp. 66-87) a maneira de pensar, por exemplo, o tema do tempo, do destino e do papel dos atores leva a acreditar que a abordagem borgeana é eminentemente estruturalista. $\mathrm{O}$ espaço de manobra ativa dos atores é limitado e o alcance que ela pode ter, em termos de mudanças no curso da história, não é significativo. Porém, em direção oposta, pensamos que esse aspecto é um pouco mais complexo no trabalho de Borges. Tomar o tempo como o tigre que te destroça e ser, ao mesmo tempo, o tigre, é ressaltar o papel ativo, porém não completamente indeterminado, dos sujeitos históricos. Ao contrário do que a leitura estruturalista de Cédola (1993, p. 41) sugere, o sujeito produtor de sentido não é negado. A leitura mais fácil do pensamento borgeano de que o nosso destino é de "irreversível", negando o papel ativo dos sujeitos, deve ser problematizada. Podemos ler os escritos de Borges mais como o desenvolvimento contínuo do debate entre agência e estrutura que se desenvolve, sobretudo, por Saussure (1959). Estamos de acordo com a leitura de Gutiérrez (2009, p. 83) quando ele nos diz que Borges "en algunas ocasiones, usó la hipótesis de la reversibilidad con fines literarios; en otras, la refutó, también con fines literarios; porque, en el fondo, creer o descreer de ella le resultaba indiferente".

8 Em sua autobiografia, Borges faz uma análise semelhante sobre a felicidade: "Ya no considero inalcanzable la felicidad como me sucedía hace tiempo. Ahora sé que puede ocurrir en cualquier momento, pero nunca hay que buscarla" (Borges, 1999, p. 154). 
que acometia o mundo na década de 1940, Borges trata, no conto "Deustsches Requiem", do livro "El Aleph" (original de 1949), do complicado tema da ação política, tendo como referência o nazismo. Ao contrário do que acontece nos outros contos discutidos, o protagonista de "Deustsches Requiem", Otto Dietrich zur Linde é um homem que não precisava de valores ou motivos para orientar suas ações, mas sim de justificativas. Ao compararmos esse conto aos outros, podemos perceber que o sonhar um homem com integridade minuciosa não precisa de justificativa. Otto é um dos raros personagens de Borges que precisava encontrar uma justificativa moral para o seu agir. Se não o fizesse, agir seria pena, perseguição insignificante de um objetivo que ele mesmo não traçou. ${ }^{9}$

Um tema que ganha relevância no pensamento de Borges e que é vital para inserir o pensamento do autor no debate que se consolidou com os termos estrutura e ação na segunda metade do século XX diz respeito à "história". Para pensar como a questão é tratada no pensamento do autor, recorremos ao texto "La doctrina de los Ciclos", que foi publicado no livro "Historia de la Eternidad" (original de 1936). Nesse trabalho percebemos a rejeição de Borges, que era um grande admirador de Schopenhauer, ${ }^{10}$ ao pensamento do "eterno retorno" de Nietzsche aplicado à história. Para ele, se o que existe é só uma repetição do que transcorreu em outro momento, não há espaço para a inovação e a capacidade de se criar coisas novas a partir de um novo momento.

[...] atribuir la menor influencia moral, vale decír práctica, a la tesis del eterno retorno, es negar la tesis - pues equivale a imaginar que algo puede acontecer de otro modo. [...] 'Basta que la doctrina de la repetición circular sea problable o posible. La imagen de uma mera posibilidad nos puede estremecer y rehacer. [...] En el instante en que se presenta esa idea, varían todos los colores - y hay otra historia' ${ }^{.11}$

9 “Deutsches Requiem" é um conto narrado em primeira pessoa por protagonista que até os 19 anos só havia lido Nietzsche e Spengler e que, aos 21 anos, entrou para O Partido Nacional Socialista Alemão. Apesar de não necessitar de valores, faltava ao protagonista "vocação" para a violência. Essa falta de vocação foi recompensada pela justificativa que encontrou para entrar no Partido, que era esperar "la guerra inexorable" que provaria a fé alemã, bastando-lhe saber que "sería un soldado de sus batallas" (Borges, 2005c, p. 108). Porém, tendo sido nomeado diretor de um campo de concentração e lá ter conhecido o poeta judeu David Jerusalem, Otto se viu a ponto de cometer o que considerava um dos maiores pecados que um homem pode perpetrar: sentir piedade por outro. A saída que ele encontrou para resolver esse impasse interno foi comportar-se de modo implacável com esse "ser" que despertava o que ele mais negava. "Ignoro si Jerusalem comprendió que si yo lo destruí, fue para destruir mi piedad. Ante mis ojos, no era un hombre, ni siquiera un judío; se había transformado en el símbolo de una detestada zona de mi alma. Yo agonicé con él, yo morí con él, yo de algún modo me he perdido con él; por eso, fui implacable" (Borges, 2005c, p. 111).

10 Borges começou a ler Schopenhauer no período de sua juventude, quando viveu na Suíça, especificamente de 1914 a 1919, justamente no período da Primeira Guerra Mundial. E, sobre esse filósofo, o autor coloca em sua autobiografia que "Hoy, si tuviera que elegir a un filósofo, lo elegiría a él. Si el enigma del universo puede formularse en palabras, creo que esas palabras están en su obra” (Borges, 1999, p. 46).

11 Borges, 2005a, p. 91. 
A história como repetição, segundo Borges, é cabível em um mundo, ou em uma parte dele, reservado aos "inmortais". Mundo esse em que a monotonia e não a inovação constante seria a regra principal. No conto "El Inmortal", que faz parte do livro "El Aleph", ${ }^{2}$ essa percepção da história dos "mortais", que é inventiva e sempre surpreendente, aparece de forma mais nítida.

Trataremos dos temas da história e da ação por meio da discussão, sobretudo de três contos do livro "Ficciones": 13 "Tlön, Uqbar, Orbis Tertius", "Las Ruinas Circulares" e "El Milagro Secreto". Do livro "El Aleph", ${ }^{14}$ uma atenção principal será dada aos contos "El Inmortal" e "Los Teólogos". Neste livro, "el tiempo", que seria o "motivo principal del pensamiento y de la estética borgeana", ${ }_{15}$ aparece como sendo um componente a mais para refletir sobre o homem e sua temporalidade. Interessa-nos pensar como, no universo criado por Borges, a ação e a história aparecem originando um resultado que é uma síntese filosófica e literária de problemas vivenciados em seu tempo que, ao contrário do que algumas análises indicam, coloca limitações para o enquadramento fácil do pensamento do autor como "estruturalista"16 predominante no tempo em que os contos foram escritos. Sustentamos que, na realidade, é só com algumas revisões do estruturalismo que acontecem nas últimas décadas do século XX é que algumas saídas já apontadas pelo labirinto de Borges ficarão mais claras.

\section{Labirintos da ação e história: partes de um quadro borgeano e contribuições posteriores}

"Tlön, Uqbar, Orbis Tertius" narra o que seria a primeira "intrusión del mundo fantástico en el mundo real". ${ }^{17}$ Embora o que constitua a ação para Borges não esteja trabalhado de maneira direta nesse conto - a saber, uma atitude que, depois de iniciada, direciona a vida do sujeito que iniciou o movimento, embora este sujeito nunca saiba, primeiramente, se seu objetivo é ou não possível de ser realizado e quais os meios que os possibilitaria atingilos -, vemos que ele nos possibilita tratar elementos que são base para entrar nos temas da ação e da história. Uqbar, que primeiramente aparece como um país forjado no século XVII, é fruto de uma sociedade secreta que planejou

\footnotetext{
12 Borges, 2005c.

13 Borges, 2005b.

14 Borges, 2005c.

15 Cédola, 1993, p. 91.

16 Visão colocada em marcha, sobretudo, por Cédola (1993).

17 Borges, 2005b, p. 14.
} 
sua criação em uma noite qualquer, também, incidentalmente, em um lugar qualquer, "Londres ou Lucerna". Por meio de alguns discípulos do grupo original, as ideias dessa sociedade chegaram à América no século XIX, porém como no Novo Mundo "es absurdo inventar un país", o responsável pela perpetuação desse movimento iniciado na Europa "propone la invención de un planeta" ${ }^{18}$ Foi a partir dessa iniciativa que surgiu a "Primeira Enciclopédia Tlön" em solo americano. Posteriormente, depois dessa invasão do mundo fantástico no mundo real, a sociedade secreta coordena uma empreitada mais audaciosa para lançar o que seria a obra mais detalhada sobre Tlön: a enciclopédia "Orbis Tertius". Escrita já não mais em inglês ou em qualquer outra língua falada pelos seres deste planeta, mas sim em várias das línguas faladas em Tlön.

Um dos traços que marca esse planeta inventado é dado por uma das únicas exigências do receptor americano responsável pela perpetuação da ideia: não permitir que essa obra pactue "con el impostor Jesucristo". ${ }^{19}$ Ao comparar esse conto com outros de Borges, no qual ele aprofunda na questão da história linear cristã, podemos ver que a negação do Cristianismo é uma característica que aponta não somente para os temas ontologia e cosmologia humana, mas para a própria possibilidade de inserção e atuação do homem no mundo, sem uma preocupação com um fim que transcenda o momento concreto de sua existência. Embora Borges não seja um adepto da visão da história como "eterno retorno" e tenha trabalhado no conto "Los Teólogos" com um suposto embate entre a história linear cristã e a história circular, ele não compartilha integralmente de nenhuma dessas visões sobre o que seria a história.

Outra característica desse planeta seria que Tlön não poderia ser ordenado racionalmente e as relações causais ali hipoteticamente estabelecidas seriam problemáticas, dada a irredutibilidade dos estados mentais:

[...] los hombres de ese planeta conciben el universo como una serie de procesos mentales, que no se desenvuelven en el espacio sino de modo sucesivo en el tiempo. [...] La percepción de una humareda en el horizonte y después del campo incendiado y después del cigarro a medio apagar que produjo la quemazón es considerada un ejemplo de asociación de ideas. [...] Explicar (o juzgar) un hecho es unirlo a otro; esa vinculación, en Tlön, es un estado posterior del sujeto, que no puede iluminar el estado anterior. Todo estado mental es irreductible. [...] Los metafísicos de Tlön no buscan la verdad ni siquiera la verosimilitud: buscan el asombro. Juzgan que la metafísica es una rama de la literatura [...]. Una de las escuelas de Tlön llega a 
negar el tiempo: razona que el presente es indefinido, que el futuro no tiene realidad sino como esperanza presente, que el pasado no tiene realidad sino como recuerdo presente". ${ }^{20}$

"Tlön, Uqbar, Orbis Tertius" pode ser visto como um conto que narra como a realidade vai cedendo espaço para o irreal, considerando que ambas são criadas pelo mesmo elemento, o homem, e impulsionadas por um mesmo movimento, a ação, que, por sua vez, ocorrem no único tempo possível, o presente. A indefinição do presente nesse conto de Borges, argumentamos, está na base da maneira como ele nos propõe pensar a história e uma despretensiosa "filosofia da história" que se tornou central no pensamento da segunda metade do século XX - esse que não compartilha das mesmas pretensões dos germinadores da ideia no século XVIII. Como Arendt diz, "a incerteza, e não a fragilidade, passa a ser a principal característica dos negócios humanos". ${ }^{21}$ Aspecto caro a Borges, pois, no quadro pintado pelo autor, a ação humana deixou de ser orientada pela projeção do telos na história e a consequente diluição da orientação metafísica desse agir. Muitas das ansiedades perceptíveis nos personagens criados, tanto no que se refere ao significado das ações que os precederam, quanto ao que suas ações podem representar no futuro, demonstram essa transformação que Borges sentia e expressava. Em seu universo, as ações criam uma rede ilimitada de novas ações que fogem completamente ao controle daquele que empreendeu o suposto primeiro movimento. Porém, novamente, compondo um labirinto mais do que um caminho linear, isso se dá em uma conjuntura na qual também possível pensar que

[...] todos los hechos que pueden ocurrirle a un hombre, desde el instante de su nacimiento hasta el de su muerte, han sido prefijados por él. Así, toda negligencia es deliberada, todo casual encuentro una cita, toda humillación una penitencia, todo fracaso una misteriosa victoria, toda muerte un suicidio. ${ }^{22}$

Quiçá se aproximando de Borges neste ponto, para Sartre, o homem é o único culpado e também único herói, de seus atos. Ao contrário de Arendt, segundo Sartre, a relação entre o existencialismo e história só ocorre porque as coisas são aquilo que o homem decidiu que elas fossem. Para Sartre "só há realidade na ação. [...] o homem não é senão o seu projeto, só existe na medida em que ser realiza, não é, portanto, nada mais do que o conjunto dos 
seus atos". ${ }^{23}$ No universo literário-filosófico borgeano, a resposta para esse problema poderia ser encontrada na maneira como o autor trabalha com a ideia de destino - "destin-ação".

$\mathrm{Na}$ singularidade de cada destino - que pode ser pensado por meio da metáfora do rio que leva e que, ao mesmo tempo, é levado - é que ação e estrutura se encontram. Colocando os problemas em termos de ação e história, evento e estrutura, os debates literalizados por Borges estiveram na base de uma das principais discussões que transformou as ciências sociais e filosóficas na segunda metade do século XX. Esse debate, da maneira desenvolvida por Sahlins, mas anteriormente promovido por Arendt e Sartre, pode ser refletido por meio da ideia de incorporação de elementos diacrônicos internos nas noções estabelecidas de estrutura. ${ }^{24}$ Para Sahlins, estruturas podem ser entendidas como formas de organização sistemática de circunstâncias contingentes e, ao mesmo tempo, a relação simbólica de um ordenamento cultural, que é histórico ${ }^{25}$ Essa visão nos ajuda a transpor as dificuldades colocadas pela proposta de Saussure na qual as "instabilidades lógicas" das categorias culturais são frutos do foco na ideia de sincronia estrutural. ${ }^{26}$ Colocando o ponto de maneira mais clara,

In a certain structuralism, history and structure are antinomies; the one is supposed to negate the other. Whereas, in the nature of symbolic action, diachrony and synchrony coexist in an indissoluble synthesis. Symbolic action is a duplex compound made up of an inescapable past and an irreducible present. An inescapable past because the concepts by which experience is organized and communicated proceed from the received cultural scheme. An irreducible present because of the world-uniqueness of any action. ${ }^{27}$

Ser conduzido pelo rio e, ao mesmo tempo, ser o rio que conduz é mostrar como circunstâncias particulares e contingentes são estruturadas. Os sujeitos que são singulares, devido à própria forma como chegam ao mundo, tornamse, na perspectiva de Arendt, ${ }^{28} \mathrm{o}$ fundamento da política que é plural e condição humana da ação. A igualdade é o aspecto que garante a possibilidade de

23 Sartre, 1973, p. 19.

24 Sahlins, 1985, p. XIV.

25 Para Sahlins, é justamente o caráter histórico que confere arbitrariedade a cada esquema linguístico, por exemplo. Nas palavras do autor: "Saussure, who was of course famous for the distinction of diachronic and synchronic viewpoints in the study of language, was nevertheless first to admit, and ever to insist, that a linguistic system is thoroughly historical. It is historical because it is arbitrary: because it does not simply reflect the existing world; but, on the contrary, in ordering existing objects by preexisting concepts, language would ignore the flux of the moment" (Sahlins, 1985, p. 148).

26 Sahlins, 1985, pp. XV-XVI.

27 Sahlins, 1985, pp. 151-152.

28 Arendt, 1987, p. 189 
compreensão mútua entre os homens; e a diferença é o aspecto que determina a necessidade do discurso e da ação para que o entendimento entre os homens seja possível. A pluralidade é percebida como o fundamento da política, especificamente, e também como a própria condição humana da ação. Com isso, a autora propõe que somente no homem e através do homem - portador da indelével característica de ser, simultaneamente, igual e diferente -, pela possibilidade de manifestação explícita de suas características, é que se garante a vida pública, fazendo com que seja possível que os homens deixem de ser meros objetos físicos para que se tornem, efetivamente, homem - ser humano. ${ }^{29}$ Sendo resgatado no calor desse debate filosófico-antropológico, ser o fogo que consome e ao mesmo tempo o próprio fogo, para Borges, pode ser uma manifestação dessa condição de pluralidade e singularidade; da maneira como, em seu esquema, o destino e a capacidade criativa se entrecruzam, de ser parte e tomar parte em conjunturas que são estruturadas e que podem se transformar a cada momento.

Com o seu empiricismo antropológico, o que Sahlins nos mostra é que, cada vez que colocamos nossas categorias recebidas de maneira prática no mundo, elas colocam em risco essas mesmas categorias. Inserir-se no mundo é colocar as categorias que recebemos em risco, inclusive nosso destino, desde o momento em que nascemos, lição que os personagens borgeanos parecem ter aprendido na prática. ${ }^{30}$

O conto "El Inmortal" fala da busca de um homem, Flaminio Rufo, para chegar até a cidade dos imortais. O que interessa notar é que, independentemente da crença na existência ou não dessa cidade, a vontade de encontrá-la era a única motivação que levou o personagem à ação - "Ignoro si creí alguna vez en la Ciudad de los Inmortales: pienso que entonces me bastó la tarea de buscarla". ${ }^{31}$ Borges mostra que a mortalidade é que confere capacidade criativa ao homem, a imortalidade é completamente fútil. É esse

29 Arendt, 1987, p. 189.

30 Embora, em termos filosóficos, as críticas ao estruturalismo desenvolvidas na França por Jacques Derrida, Gilles Deleuze e Jean-François Lyotard sejam os trabalhos mais expressivos e influentes, para, inclusive criar a imagem de que o problema borgeano foi desenvolvido em áreas mais diversas e empíricas, o argumento deste artigo é estruturado, principalmente, por meio da discussão de Sahlins (1985) sobre estrutura (história) e ação. Argumentamos que nos contos de Borges discutidos a ideia de "estrutura da conjuntura" é uma das que mais nos ajuda a elucidar o debate entre ação e história. Falar de estrutura da conjuntura é tratar da "practical realization of cultural categories in a specific historical context, as expressed in the interested action of the historic agentes" (Sahlins, 1985, p. XIV). O antropólogo afirma, em termos empíricos, a ideia que as ações são criativamente estruturadas, pois, ao mesmo tempo em que representam a continuidade de algo estruturado, colocam em risco nas suas formas de atualização prática as categorias recebidas. Em termos borgeanos, embora o destino seja dado, os agentes, em sua atualização cotidiana, colocam em risco os pontos tomados como certo.

31 Borges, 2005c, p. 11. 
fato, morte e nascimento dos homens, que dá início a uma nova ação, que os torna singulares. ${ }^{32}$ Nesse conto, a busca pela Cidade dos Imortais foi longa e exigiu de Flaminio Rufo muita resistência e força para superar todos os obstáculos físicos e psicológicos que enfrentou no trajeto. Depois de atravessar dificuldades de diversos tipos, a tão buscada cidade onde viviam apenas trogloditas - "hombres de piel gris, de barba negligente y desnudos" 33 - que não falavam e se alimentavam de cobras, foi, enfim, encontrada. Apesar das dificuldades do trajeto, decepcionado, Flaminio ficou pouco tempo no local. Um dos trogloditas o seguiu até a saída da Cidade dos Imortais. Depois de se ver completamente frustrado em todas as tentativas propedêuticas de ensinar comportamentos básicos que até um "cachorro" aprenderia ao seu seguidor, Flaminio se viu instigado por uma, enfim, manifestação. O troglodita, chamado por ele de Argos, nome inspirado no "viejo perro moribundo de la Odisea", depois de uma chuva que os acometeu e fez com que "el perro" recordasse alguma coisa de humano que existira nele, disse a Flaminio: "Argos, perro de Ulises. [...] Este perro tirado en el estiércol". ${ }^{34} \mathrm{Na}$ continuidade do diálogo, enfim, estabelecido, o protagonista nos diz que

Fácilmente aceptamos la realidad, acaso porque intuimos que nada es real. Le pregunté qué sabía de la Odisea. La práctica del griego le era penosa; tuve que repetir la pregunta. 'Muy poco', dijo. 'Menos que el rapsoda más pobre. Ya habrán pasado mil cien años desde que la inventé'. ${ }^{35}$

A conexão mais nítida entre a visão borgeana sobre ação e a história e a proposta de Arendt de colocar o problema em termos de singularidade e pluralidade aparece nessa passagem em que Flaminio descobre que troglodita era Homero. O encontro com Homero em tais circunstâncias fez com que o protagonista reafirmasse sua visão de que a imortalidade é um castigo para os homens, pois caem no ostracismo até de si mesmos e desistem de agir por terem chegado à conclusão de que tudo é uma mera repetição do que ocorrera anteriormente. A aceitação de que a história é circular, o que na visão de Borges só é aplicável aos imortais, pode originar somente monotonia, inação e esquecimento. A singularidade se perde.

Ser inmortal es baladí; menos el hombre, todas las criaturas lo son, pues ignoran la muerte; lo divino, lo terrible, lo incomprensible es saberse inmortal. [...] Adoctrinada 
por un ejercicio de siglos, la república de los hombres inmortales habría logrado la perfección de la tolerancia y casi del desdén. Sabía que en un plazo infinito le ocurren a todos los hombres todas las cosas. Por sus pasadas o futuras virtudes, todo hombre es acreedor a toda bondad, pero también a toda traición, por sus infamias del pasado o del porvenir. ${ }^{36}$

O embate entre diferentes concepções filosóficas de qual a melhor metáfora descreve o funcionamento da história fica mais nítida no conto "Los Teólogos". Essa é uma narrativa que trata da luta entre a roda - história circular - e a cruz - história que termina e se cumpre em cada ser humano -, a partir do embate entre dois estudiosos da relação dos homens com o universo divino. Aureliano, um dos teólogos, assim como Nietzsche, tentava provar a tese da "circularidade" da história. Para ele, "la historia es un círculo y que nada es que no haya sido y que no será". ${ }^{37}$ Sua tese, no conto, é refutada pela de Juan de Panonia, que defendia que "El tiempo no rehace lo que perdemos; la eternidad lo guarda para la gloria y también para el fuego". ${ }^{38}$ Assim, em um primeiro momento, "Cayó la Rueda ante la Cruz", porém, para Borges, o resultado final dessa briga só pode ser referido em metáforas, pois ela se passa "en el reino de los cielos, donde no hay tiempo". ${ }^{39}$

A concepção de estrutura presente na obra de Borges parte da constatação de que ela mesma só pode ser pensada em um terreno no qual a ação humana, a inovação e a contingência fazem parte da própria gênese histórica. A história é contingência e invenção, não no sentido de que, na ausência de uma aceitação irrefutável da fórmula historia magistra vitae atribui-se um status subjetivista extremamente pretensioso. ${ }^{40}$ Esse caráter da história se origina no fato de ela ser feita por homens. E, com Arendt, vimos que o grande enigma da história residiria justamente nesse jogo entre singularidade e pluralidade.

$\mathrm{O}$ fato de que toda vida individual, compreendida entre o nascimento e a morte, pode vir a ser narrada como uma história com princípio e fim, é a condição pré-política e pré-histórica da História, a grande história sem começo e sem fim. Mas o motivo pelo qual toda vida humana constitui uma história e pelo qual a História vem a ser, posteriormente, o livro de histórias da humanidade, com muitos atores e narradores, mas sem autores tangíveis, é que ambas resultam da ação. Pois a grande incógnita da História, que vem desafiando a filosofia da História na era moderna, não surge

36 Borges, 2005c, p. 22.

37 Ibidem, p. 41.

38 Ibidem, p. 44.

39 Ibidem, pp. 45 e 51, respectivamente. Na conclusão do artigo o tema será retomado.

40 Ver Koselleck, 2006; Gumbrecht, 1999. 
somente quando consideramos a História como um todo e descobrimos que o seu sujeito, a humanidade, é uma abstração que jamais pode ser um agente ativo. ${ }^{41}$

No conto "Las Ruinas Circulares", Borges explora a busca de outro personagem cujo único objetivo, que não pode ser caracterizado como "imposible, aunque sí sobrenatural", ${ }^{42}$ era sonhar um homem e submetê-lo à realidade. Tanto nesse conto, quanto em "El Inmortal", os protagonistas executam ações que são importantes e devem ser postas em marcha, independentemente da possibilidade concreta de realização dos objetivos a que eles se propõem. Nos dois contos, os projetos traçados consumiram a vida dos protagonistas. Em "Las Ruinas Circulares", o protagonista esqueceu o seu próprio nome e qualquer outra característica que dissesse respeito à sua personalidade antes de se propor a esse objetivo. Ele viajou até um local distante, que ficava ao norte de sua terra original, para poder encontrar um espaço sagrado ou algo semelhante a isso, onde sonhar um homem íntegro fosse possível. O sonhador fracassou na primeira tentativa deliberada de dormir profundamente para poder sonhar com esse homem. Assim, ele

comprendió que el empeño de modelar la materia incoherente y vertiginosa de que se componen los sueños es el más arduo que puede acometer un varón, aunque penetre todos los enigmas del orden superior y del inferior [...]. Comprendió que un fracaso inicial era inevitable. Juró olvidar la enorme alucinación que lo había desviado al principio y buscó otro método de trabajo. [...] Abandonó toda premeditación de soñar y casi acto continuo logró dormir un trecho razonable del día. [...] Luego, en la tarde, se purificó en las aguas del río, adoró los dioses planetarios, pronunció las sílabas lícitas de un nombre poderoso y durmió. Casi inmediatamente, soñó con un corazón que latía. ${ }^{43}$

Seria possível dizer que essa narrativa é, ao mesmo tempo, uma ode à natureza eminentemente "essencial" do ser humano e à abertura do acaso, transformação do tempo "irreversível" em cada um dos eventos que lhe perpassam. Além de uma aproximação entre Borges e Sartre, por meio desse conto é possível resgatar elementos do debate estabelecido entre Sartre e Heidegger ${ }^{44}$ sobre o humanismo e o existencialismo, lembrando-nos a posição de Heidegger sobre a tentativa sempre fracassada de o ente conseguir chegar ao Ser de maneira deliberada, dispensando qualquer subjetivismo como sendo 
o responsável por se construir algo novo. O existencialismo sartreano advoga que a existência subjetiva do homem precede a sua essência e que

[...] o primeiro esforço do existencialismo é o de pôr todo homem no domínio do que ele é e de lhe atribuir a total responsabilidade sobre sua existência. E, quando dizemos que o homem é responsável por si próprio, não queremos dizer que o homem é responsável pela sua própria individualidade, mas que é responsável por todos os homens..$^{45}$

Para Heidegger, ao contrário, a essência do agir é consumar algo que já é, "O pensamento con-suma a referência do Ser à Essência do homem. Não a produz nem a efetua". ${ }^{46}$ Assim como o protagonista do conto se frustrou na primeira tentativa deliberada de alcançar seu objetivo, para Heidegger, o pensamento deve se deixar livre para pensar, sem as amarras restritivas da técnica. Sempre que uma intenção deliberada de se alcançar o Ser for empreendida, Ele se esconderá. É de sua própria natureza se desvelar quando o pensamento estiver livre, sem rédeas. Para Heidegger, Sartre, ao dizer que a existência (existentia) precede a essência (essentia), adota um sentido metafísico, modo de "pensar" que Heidegger recusa. ${ }^{47}$ Entretanto, como vimos, no emaranhado borgeano, existe espaço para o resgate saudosista de uma metafísica de "tipo básico" subjacentemente à adoção da ideia de que o pensamento que deve ser livre, sem constrangimentos calculistas, para ser o que já é.

No conto de Borges, "el corazón que latía", em cada sonho, o sonhador ganhava concretude humana e uma integridade que não correspondia às persistentes deficiências físicas que possuía. Depois de feitos os devidos ritos que o inseririam no universo, "en el sueño del hombre que soñaba, el soñado se despertó". ${ }^{48}$ Apesar de esse processo ter sido desejado e perseguido, foi muito difícil aceitar o fato. Embora fosse esse o objetivo inicial do homem que sonhava, para ele não foi fácil deixar de "possuir" o homem sonhado. Pretextos pedagógicos e de correção das imperfeições físicas foram criados para fazer com que a dor de se distanciar do seu "hijo" não chegasse de maneira tão abrupta. Porém, o sonhador progressivamente foi se acostumando com o feito de que uma hora o homem sonhado deixaria de depender dele para existir. Em uma determinada noite, o sonhador "lo besó por primera vez y lo envió a otro templo [...]. Antes (para que no supiera que era un fantasma, para que se creyera un hombre como los otros) le infundió el olvido total de sus 
años de aprendizaje". ${ }^{49}$ A magia maior do conto está no dia em que o sonhador se descobre também sonhado por outro homem.

\section{Debates contemporâneos sobre história e ação: palavras finais}

De acordo com Bodei, "A atual crise do telos da história, em que se proclama a perda de visibilidade de qualquer meta, está na realidade latente há pelo menos 150 anos, desde o tempo dos primeiros discípulos e adversários de Hegel até Dilthey e Nietzsche". ${ }^{50}$ Porém, uma discussão crítica mais explícita sobre o tema só aparecerá na segunda metade do século XX. Nesse mesmo debate, mas levando a discussão para outro terreno, Koselleck, ${ }^{51}$ no texto "Terror e Sonho", trata da diferenciação e aproximação entre os elementos que ligam a res factae - "realidade dos fatos ou ocorrência" - e a res fictae - "realidade das ações inventadas". Segundo o autor, essa separação entre história e poesia, que reconhecia a importância de cada um dos campos, preponderou até o século XVIII. "A poesia visa ao possível e ao geral, se aproxima da filosofia, ao passo que a história (Historie) se orienta unicamente pelo decurso do tempo". ${ }^{52}$ O Iluminismo teria sido o responsável por inaugurar novo momento, no qual as fronteiras que tendiam a demarcar os campos de atuação da res factae e da res fictae não seriam mais tão nítidas. "Logo que se viu forçado a construir com arte sua história, a dar-lhe fundamentos morais e racionais, o historiador passou a depender dos recursos da ficção". ${ }^{53} \mathrm{~A}$ construção de teorias, que marcaria a forma como o historiador deveria olhar para a história, também marcou esse período e contribuiu decisivamente para essa dissolução das fronteiras.

A ação, o homem e a história estão completamente entrelaçados no pensamento que mistura a res factae e a res fictae de Borges. Nos contos discutidos, o homem aparece enquanto essência - conceito não redutível apenas à subjetividade - mais do que existência - concretude -, e as ações que empreendem bem como os cursos possíveis a que tais ações podem conduzir são contingentes, mas, nem por isso, desestruturados. Ao contrário, o que é fascinante nesses contos é que os personagens principais sempre buscam alguma coisa independentemente de qualquer garantia ou controle sobre os resultados aos quais suas ações podem levar. Eles seguem buscando e veem

49 Borges, 2005b, p. 28.

50 Bodei, 2001, p. 55.

51 Koselleck, 2006, pp. 247-251.

52 Ibidem, p. 247.

53 Ibidem, p. 248. 
na própria busca formas significativas de se inserir no mundo. Como os personagens criados por Borges demonstram, a ação possibilita que projetos sejam consumados, porém não enquanto projetos com fins em sim, mas como coisas que consumam algo que já existia, aspecto que fica nítido nos contos "Los Inmortales", no qual o personagem principal descobre o fascínio da mortalidade, e "Las Ruinas Circulares", cujo protagonista conseguiu realizar uma suposta grande invenção, a qual, contudo, levou-o ao descobrimento do que ele mesmo era.

A negação de uma ideia de história circular, como sendo algo que ceifaria qualquer possibilidade de ação criativa do homem no mundo, e também de um sentido teleológico na história que orientaria as ações humanas, embora não seja aspecto tão excepcional que tornaria a obra de Borges única, é uma característica que ajuda a vislumbramos certo vanguardismo no pensamento que o autor nos transmite. Assim, contudo seja verdade que "hoje são poucos os que creem, por raciocínio e não por fé, que a história tenha um sentido", ${ }^{54}$ não sendo, portanto, grande novidade pensar nesses termos, Borges conseguiu tratar desse aspecto englobando uma visão filosófica de homem e de ação de forma diferenciada nesse contexto no qual o pensamento estruturalista se via fortificado. A opção por escrever contos a partir da década de 1930, como consta na sua autobiografia, foi tomada por Borges, pois ele gostaria de escrever de forma mais livre do que os poemas e os romances permitiam, mas, ao mesmo tempo, garantindo que a sistematicidade das grandes narrativas não fosse perdida, o que, seguramente, encaixava-se bem nessa maneira de discutir os temas do humano e de sua ação através do tempo.

Borges pode ser encaixado na definição de Bodei ${ }^{55}$ do que seria um libertino: aquele que pensa de forma "espontânea" e "livre", que não tem pretensão nenhuma de se adaptar às convenções de seu tempo, sobre temas importantes para a filosofia, como a história, a humanidade e o mundo. $\mathrm{O}$ papel que esses sujeitos desempenham é de grande importância para que os paradigmas sejam quebrados e novas possibilidades de interpretação e reflexão sobre o mundo sejam possíveis. Na releitura dos contos de Borges, talvez possamos ver uma manifestação daquilo que Heidegger ${ }^{56}$ chama do pensamento livre para pensar, sendo, portanto, uma forma de compreender que um processo tem sido refletido dentro das amarras da técnica científica, por um viés, talvez, menos constrangido. 
Nos contos trabalhados, observamos vários elementos da discussão sobre a quebra do paradigma da história enquanto um curso racional orientado por um fim perceptível e necessário, e o tema das ações humanas. Ao contrário do que os propulsores do movimento que ficou conhecido como "Nova História", para os quais "escrever a História significa fazer História", ${ }^{57}$ nos contos borgeanos, pensados à luz de propostas filosóficas e antropológicas discutidas subjacentemente neste artigo, sentir a quebra do paradigma estrutural da história é trazer a contingência e a arbitrariedade para o primeiro plano, mas sem assumir a superpotência dos sujeitos e de suas ações. Essa superpotência dos sujeitos, argumentamos, é diminuída no pensamento de Borges por meio do uso literário da temática da "destinação". Nos contos analisados, talvez, o que esteja na base da busca incessante e incontrolável que marca a vida dos personagens seria que eles agem, pois não há outra opção. Estão inseridos em teias que os levam a isso. Porém, e sobretudo, o espaço para ação criativa não é apagado. É possível se decepcionar com a cidade encontrada e deixála; é possível, por meio da experiência, saber qual o melhor "método" para se sonhar o sonho buscado etc. Embora esse seja um esforço de síntese arriscado e, pela própria natureza, incompleto, podemos ver que o argumento levantado na introdução ao artigo - de que o labirinto borgeano nos leva a todo momento para cenários nos quais o debate entre ação e história se apresenta como enigma - vemos que o universo do autor se aproxima das contribuições arendtianas, que apareceram no mesmo momento em que Borges escrevia, e foram avançadas por autores como Koselleck e Sahlins, para ficar somente com os discutidos neste artigo, em momento posterior trabalhando nos campos da filosofia da história e da antropologia. Agir é colocar as categorias em risco e, como nosso destino é seguir agindo, as estruturas históricas são sempre sujeitas à ousadia criativa humana.

\section{Referências}

ARENDT, H. “A condição humana". Rio de Janeiro: Forense-Universitária, 1987. BODEI, R. “A História Tem um Sentido?” Bauru: EDUSC, 2001. BORGES, J. L. “Autobiografía: 1899-1970”. Buenos Aires: El Ateneo, 1999 [1970 Autobiographical Essay].

. "Historia de la Eternidad". Buenos Aires: Emecé Editores, 2005a. (Edição especial para La Nación). 
BORGES, J. L. "Ficciones”. Buenos Aires: Emecé Editores, 2005b. (Edição especial para La Nación).

La Nación).

. "El Aleph". Buenos Aires: Emecé Editores, 2005c. (Edição especial para

BOSSART, W. H. "Borges and Philosophy: self, time, and metaphysics". Nova York:

Peter Lang Publishing, 2003.

CÉDOLA, E. "Borges o la coincidencia de los opuestos". $2^{\mathrm{a}}$ ed. Buenos Aires: EUDEBA, 1993.

GUMBRECHT, H. U. "Em 1926: vivendo no limite do tempo". Rio de Janeiro; São Paulo: Record, 1999.

GUTIÉRREZ, E. "Borges y los Senderos de la Filosofía". Coleção Pampa Aru. Buenos Aires: La Cuarenta, 2009.

HEIDEGGER, M. "Sobre o humanismo". $3^{\text {a }}$ ed. Rio de Janeiro: Tempo Brasileiro, 2009.

KOSELLECK, R. "Futuro Passado: contribuição à semântica dos tempos históricos". Rio de Janeiro: Contraponto: Ed. PUC-Rio, 2006.

MACHEREY, P. "Borges y el relato fictício". Revista Nuevos Aires, Buenos Aires, Nr. 04, 1971.

MICELI, S. "Jorge Luis Borges: história social de um escritor nato". Novos Estudos CEBRAP, 77, pp. 155-182, mar. 2007.

SAHLINS, M. "Islands of History". Chicago: Chicago University Press, 1985.

SARTRE, J.-P. "O Existencialismo é um Humanismo". Coleção Os Pensadores, Vol. XLV. São Paulo: Abril S.A. Cultural, 1973.

SAUSSURE, F. "Course in General Linguistic”. New York: MacGraw-Hill, 1959. 